Gut, 1961, 2, 82

\title{
The Nile blue test in the detection of steatorrhoea
}

\author{
J. POLYZOS AND T. D. KELLOCK
}

From the Department of Gastroenterology, Central Middlesex Hospital, London

SYNOPSIS The Nile blue test for the detection of steatorrhoea has been compared with the estimation of 24-hour faecal excretion by the method of Weijers and Van der Kamer modified by Anderson, Frazer, French, Gerrard, Simmons, and Smellie (1952). The Nile blue test is easily and quickly carried out. A positive result was only found in cases showing a considerable degree of steatorrhoea but it was often negative when the excretion of fat was abnormally high. This test appears to be of considerable use as a rapid, semiquantitative screening test in the investigation of possible cases of steatorrhoea.

The usual laboratory methods for the estimation of fat in faeces are accurate but extremely time consuming. In Great Britain the method most used is that of Weijers and Van der Kamer, as modified by Anderson, et al. (1952). In this method the output of fat in 24 hours is estimated by analysis of an aliquot of faeces collected over a known period. This is almost certainly the most accurate method available, but takes two and a half to three hours for each estimation, and there is no means of 'bulking' the tests, so that a number may be carried out simultaneously. Consequently, to carry out a number of such estimations throws a heavy burden on any laboratory. The same objections apply to other clinical methods, and therefore the estimation of the stools for fat is probably not undertaken as often as it should be.

A number of ways have been suggested as qualitative rather than quantitative tests for excess faecal fat. The naked-eye inspection of the stools is often enough for diagnosis, but there are cases in which the appearance is remarkably normal even though the fat content may be high. Microscopic examination of the stools for fat crystals and fat droplets has been used extensively in the past as a rapid screening test for excessive fat but this is very inaccurate, as has been shown by Demole and Thommen (1949).

For these reasons a rapid, semi-quantitative test for faecal fat would be of great clinical value for the diagnosis of steatorrhoea. Demole and Howard (1958) have applied the Nile blue reaction as a test on these lines. This is based on the principle that Nile blue in the presence of sodium carbonate gives a blue colour with oleates, and the depth of this colour will be proportionate to the amount of oleates present. These authors compared this test with quantitative estimations of the percentage of fat in the faeces, as estimated by the modified (Anderson et al., 1952) method of Weijers and Van der Kamer. They found a good correlation between the tests. The percentage of fat in the faeces, however, is not usually held to be the best guide to the pathological quantities of fat being excreted, and it seemed that it would be worth while attempting to correlate the Nile blue test with the 24-hour faecal fat excretion.

\section{METHOD}

The method used for the Nile blue reaction was the same as that described by Demole and Howard (1958), and was originally described by Goiffon (1948).

REAGENTS $\quad 0.05 \%$ Nile blue $20 \%$ pure sodium carbonate $10 \%$ hydrochloric acid

Saturated aqueous solution of ammonium oxalate

\section{PROCEDURE}

Faeces to be examined are diluted to a concentration of approximately $10 \%$, and mixed well. To $1 \mathrm{ml}$. of this dilute faecal suspension is added in a test tube $1 \mathrm{ml}$. of distilled water, 2 drops of $10 \% \mathrm{Hcl}$, and 1 drop of the saturated solution of ammonium oxalate. The mixture is heated to boiling for a few seconds, then cooled and poured into a $25 \mathrm{ml}$. beaker. The test tube is washed with $2.5 \mathrm{ml}$. of sodium carbonate, and the washings poured into the beaker until the total volume is $20 \mathrm{ml}$., when $1 \mathrm{ml}$. of Nile blue is added.

A single estimation takes 15-20 minutes, and a number of estimations can be carried out simultaneously. The colour of the mixture is read immediately. The colours range from pink-grey $(O)$ through grey blue $(+)$ light blue $(++)$ to deep blue $(+++)$. The total faecal fat 


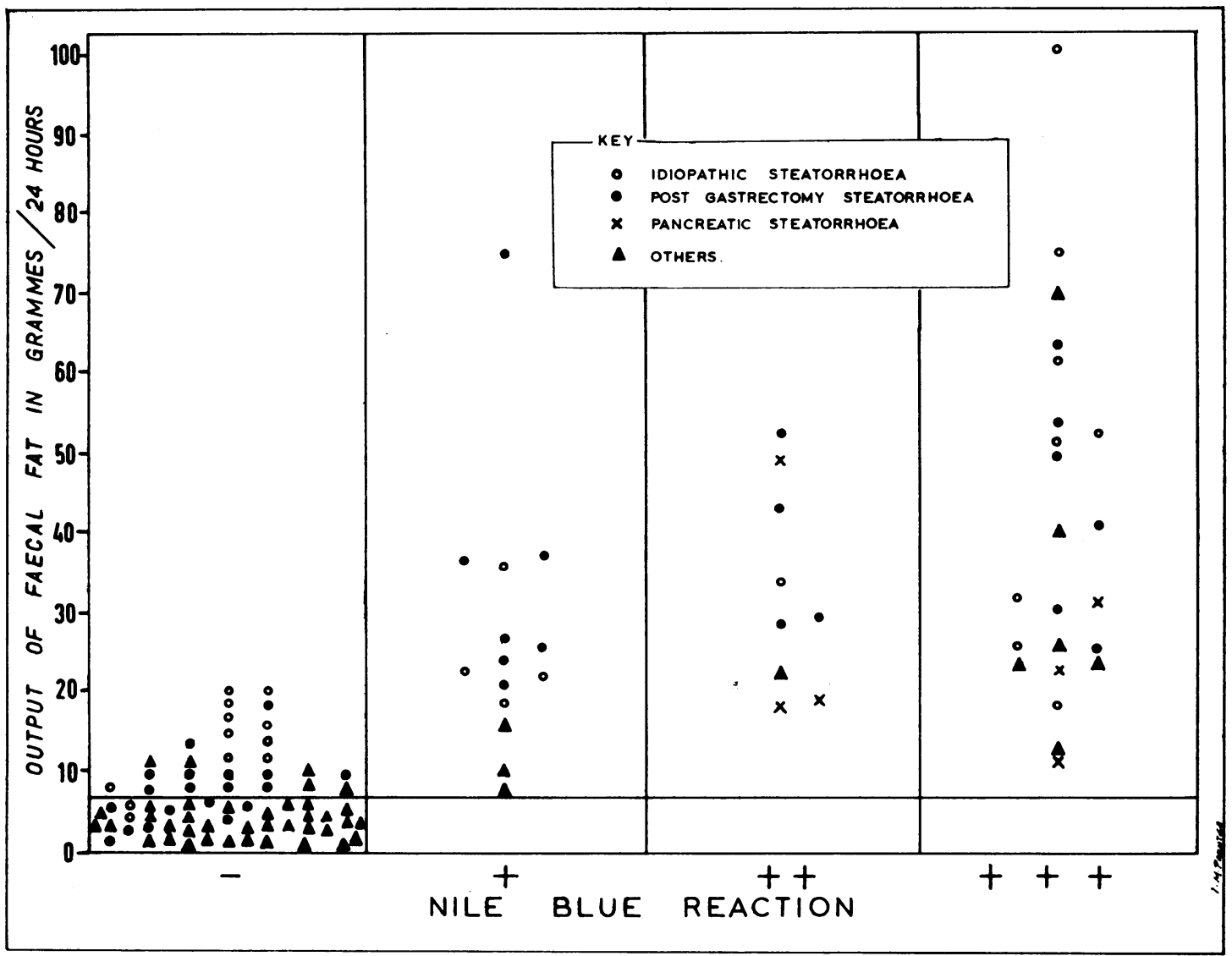

in 24 hours was estimated by the modified method of Weijers and Van der Kamer (Anderson et al., 1952).

The faeces investigated were an unselected series of specimens received in the laboratory for faecal fat estimation and were from patients with a variety of clinical conditions.

One hundred and sixteen specimens were examined from some 80 patients. Each specimen consisted of a three-day collection of faeces from patients on mormal hospital diet.

\section{RESULTS AND DISCUSSION}

The results are shown in the table and the figure.

In every case in which the Nile blue test was positive there was more than $7 \mathrm{~g}$. of fat in the 24hour stool. On the other hand, the test was frequently negative when the 24-hour output was pathologically high. In two cases a 24-hour output of nearly $20 \mathrm{~g}$. gave a normal Nile blue test. Although the ranges in each group are great, the colour reaction increases in parallel with the 24-hour faecal fat. It will be noted that one case, giving only a $1+$
TABLE

RESULTS OF FAECAL FAT ESTIMATION BY MEANS OF NILE BLUE REACTION COMPARED WITH RESULTS OF CHEMICAL ANALYSIS

\begin{tabular}{|c|c|c|c|c|}
\hline \multirow{2}{*}{$\begin{array}{l}\text { No. of } \\
\text { Examina- } \\
\text { tions }\end{array}$} & \multirow{2}{*}{$\begin{array}{l}\text { Nile } \\
\text { Blue } \\
\text { Reaction }\end{array}$} & \multicolumn{3}{|c|}{ Chemical Reaction Fat Output (g.j24 hr.) } \\
\hline & & Minimum & Average & Maximum \\
\hline $\begin{array}{r}70 \\
14 \\
9 \\
23\end{array}$ & $\begin{array}{c}\overline{+} \\
++ \\
+++\end{array}$ & $\begin{array}{c}0.57 \\
7 \cdot 1 \\
17 \cdot 8 \\
11 \cdot 17\end{array}$ & $\begin{array}{c}6 \cdot 7 \\
26 \cdot 39 \\
32 \cdot 47 \\
40 \cdot 58\end{array}$ & $\begin{array}{r}19.8 \\
74.8 \\
52.3 \\
113.7\end{array}$ \\
\hline
\end{tabular}

Nile blue reaction had a faecal fat content of 75 g./24 hours. This specimen was analysed by gas chromatography and the percentage of oleates was unusually low, accounting for only $9 \%$ of the total fatty acids. This is a lower percentage than has been encountered in any other case investigated, and appears to confirm that it is the oleates that are responsible for the Nile blue reaction.

There would appear to be little relationship between the type of disease producing the steatorrhoea and the results of the tests. The cases of pancreatic 
steatorrhoea do show a rather strong Nile blue reaction proportionate to the amount of the 24-hour faecal fat, but only six cases of this type of steatorrhoea were investigated and this may well be a chance relationship rather than an indication that there are relatively more oleates in the faecal fat of these patients than in that of those suffering from other types of steatorrhoea.

The results suggest that a positive Nile blue test is indicative of a pathological degree of steatorrhoea, and as the time taken for this test is only a fraction of that needed for quantitative chemical analysis by the accepted methods, this test could prove a useful screening test in the investigation of cases of diarrhoea and anaemia. It does not, however, in its present form offer a means of excluding such a diagnosis, as a considerable degree of steatorrhoea (as assessed by a 24-hour faecal fat) may be associated with a negative Nile blue test.

\section{REFERENCES}

Anderson, C. M., Frazer, A. C., French, J. M., Gerrard, J. W., Simmons, H. G., and Smellie, J. M. (1952). Lancet, 1, 836-842. Demole, M. J., and Howard, E. M. (1958). Amer. J. dig. Dis., n.s.3, 549-556.

_, and Thommen, B. (1949). Arch. Mal. Appar. dig., 38, 1128-1132 Goiffon, R. (1948). Ann. Biol. clin., 6, 282.

\section{The December 1960 Issue}

\section{THE DECEMBER 1960 ISSUE CONTAINS THE FOLLOWING PAPERS}

\begin{abstract}
Heredity in Gastroenterology: A Review R. B. MCCONNELL

Use of Soframycin (Framycetin Sulphate) for Intestinal Sterilization N. E. STIDOLPH and J. M. ALSTON
\end{abstract}

Clinical and Genetic Problems in Familial Intestinal Polyposis A. M. O. VEALE

The Distribution of Ulcerative Colitis and Regional Enteritis in Unites States Veterans with Particular Reference to the Jewish Religion E. D. ACHESON

An Assessment of the Value of Serum Cholinesterase as a Liver Function Test and in the Diagnosis of Jaundice WILLIAM BURNETT

Serum Albumin, Pseudocholinesterase, and Transaminases in the Assessment of Liver Function Before and After Venous Shunt Operations ALAN H. HUNT and HERMANN LEHMANN

Aneurysm of the Splenic Artery P. D. BEDFORD and BRIAN LODGE

A Case of Spontaneous Rupture of the Normal Large Bowel Causing Haemoperitoneum c. T. HOWE
The Augmented Histamine Test with Special Reference to Achlorhydria SHEILA T. CALLENDER, F. P. RETIEF, and L. J. WITTS

Some Factors in the Assessment of Gastric Antisecretory Drugs by a Sampling Technique J. P. BINGLE and J. E. LENNARD-JONES

The Effect of an Adrenal Inhibitor (SU 4885) on Gastric Secretion in Dogs J. W. McINTOSH, N. ANDERSON, H. L. DUTHIE, and A. P. M. FORREST

Intraoesophageal Adenocarcinoma o. G. DODGE

Percutaneous Transhepatic Cholangiography MICHAEL ATKINSON, MARGARET G. HAPPEY, and FRANCIS G. SMIDDY

Radiological Investigation of the Small Intestine by Small Bowel Enema technique F. PYGOTT, D. F. STREET, M. F. SHELLSHEAR, and C. J. RHODES

Gastroenter ological Society of Australia Index to Volume I

Copies are still available and may be obtained from the PUBLISHING MANAGER, BRITISH MEDICAL ASSOCIATION, TAVISTOCK SQUARE, W.C.1, price 17s. 6D. 